\title{
COASTAL STORM INDUCED EROSION PREDICTIONS FOR FEMA FIS COASTAL HAZARD RISK MAPPING
}

\author{
Christina Lindemer ${ }^{1}$ Jeffrey Gangai ${ }^{2}$ Christopher Mack ${ }^{3}$ Elena Drei-Horgan ${ }^{3}$ Darryl Hatheway ${ }^{3}$ \\ Flood Insurance Studies (FISs) produced by the Federal Emergency Management Agency (FEMA) per the National \\ Flood Insurance Program (NFIP) regulations and guidelines adopt storm-induced erosion criteria often called the \\ "540 rule". The methods used in the erosion analysis have been in place since the $1980 \mathrm{~s}$. The method requires dunes \\ to be classified as fully eroded, or "removed", when their cross-sectional reservoir is smaller than 540 square feet. \\ Since the rule's first application, additional data and recent evidence have become available leading FEMA to \\ identify this approach as an area of the program in need of updating and improvement. Experts involved in \\ conducting coastal hazard analyses for FEMA studies recommend exploring opportunities to improve FEMA \\ guidelines for erosion criterion and revise NFIP regulations and guidance, as needed, to ensure that storm-related \\ erosion hazards are appropriately evaluated and mapped along US coastlines.
}

Keywords: erosion, dune, FEMA, policy, regulation, extreme storm events

\section{Introduction}

Today's FEMA coastal Flood Insurance Studies (FIS) and digital Flood Insurance Rate Maps (FIRM) integrate decades of engineering, science, and guidance for identifying and mapping Special Flood Hazard Areas (SFHA). Two aspects of mapping the SFHA that are unique to coastal hazard analyses are:

1. The identification of Primary Frontal Dunes (PFD), and

2. Erosion analyses on the nearshore due to elevated water levels and wave action during a storm event.

These aspects help identify the Coastal High Hazard Area (CHHA) or V-Zone, an area known to have exposure to extreme coastal hazards such as 3 foot breaking waves. These areas are subject to storm-induced beach and dune erosion and require protection from man-made alteration of dune.

Both the identification of the Primary Frontal Dune and the majority of erosion analyses on the open coast focus on sandy beach and dune erosion. Dunes provide multiple ecological benefits and services, while also providing a natural or manmade defense against coastal storm surge. Dunes dissipate waves that would otherwise cause severe damage to landward properties and buildings. Dunes, although sacrificial due to storm induced erosion along the shorelines, can be a significant factor in the determination and mapping of coastal flooding risks to the natural and built environment, as they can control the amount of surge and wave energy able to move inland.

FEMA established a method for determining storm induced erosion that originated in the 1980s, based on pre- and post-storm observations and comparative analyses, and known inadequacy in previous modeling and mapping procedures along the coastline. This erosion analysis method has been under increasing scrutiny due to:

1. an additional period of record of storm-induced erosion data,

2. the method uses only a mean erosion rate of 540 square feet per linear foot of shoreline,

3. the current age of numerical methods,

4. stringent criteria set in federal regulations, and

5. the associated challenges in flood hazard mapping related to the PFD.

Because of the importance of the dunes in protecting inland areas, and the uncertainty in the amount of erosion that can occur during extreme storm events, the dunes identified as Primary Frontal Dunes are automatically designated and extend a V-Zone inland to the landward heel of the PFD. Areas within V-Zones require more stringent building standards, adequate insurance rates, and are often protected in the adopted floodplain ordinance to prevent man-made alteration or destruction of the dunes. The location of landward limit of a calculated V-Zone is typically based on wave data and an erosion assessment (e.g., overland waves, wave runup, topography, aerial photos, and field reconnaissance), but also engineering judgment since the PFD is an ephemeral feature and in many locations has been impacted by development or previous storms. Consequently, the identification and

\footnotetext{
${ }^{1}$ Federal Emergency Management Agency, 400 C Street SW, Washington, DC, 20024, United States

2 Dewberry, 8401 Arlington Blvd, Fairfax, VA, 22031, United States

${ }^{3}$ AECOM, 1999 Avenue of the Stars, Los Angeles, CA, 90067, United States
} 
designation of the PFD for FEMA coastal flood studies has come under scrutiny and is the basis of many comments and appeals from communities.

As the criteria for storm-induced dune erosion assessment (540-SF) and the creation of the PFD originated from methodology and programmatic needs of the 1980s, a refresh is needed to improve technical credibility to coastal hazard mapping. Besides an additional 30 years of pre- and post-storm erosion data, more robust and more cost-effective methodologies exist now to calculate storm-induced erosion, which did not exist at the time of the federal regulations being codified. While the application of the methods and mapping were simplified, they served FEMA well. However, the codification of the PFD and erosion criteria, in 44 CFR made it challenging to study partners and floodplain managers to explore other erosion methodologies and more appropriate (defendable) V-Zone hazard mapping along the coastline. Consequently, the PFD criteria and erosion assessment methodology should be removed from 44 CFR.

Echoing similar sentiments on the inadequacy of current storm-induced erosion methodologies and PFD mapping, external partners such as the Technical Mapping Advisory Council (TMAC) have continued to voice that updates to the adopted and recommended methodology are necessary. With the program moving toward modern, robust and tailorable erosion methodologies, today's approaches may eliminate the need for continuing to designate the PFD as a V-Zone. Today, sound quantifiable analyses and best available data should be encouraged (not codified) for use in depicting coastal hazards versus a somewhat arbitrary designation.

This paper is intended to highlight some of the issues encountered in applying the current erosion methodology and delineating the PFD V-Zone. The issue paper will also make a case for addressing the issues and developing new guidelines and methods for determining storm induced erosion for FISs. Changes to both erosion methodology and the insurance implications with respect to the PFD are recommended to be well vetted and based in sound engineering judgement. With a robust analysis, accurate erosion estimates can be provided to help ensure informed decisions are made regarding the resilience of the nation's coastline to erosional hazards.

\section{History of Storm Induced Erosion and Primary Frontal Dune}

The National Flood Insurance Program (NFIP) was passed by the Congress of the United States in 1968 under the National Flood Insurance Act of 1968 (P.L. 90-448). The NFIP provides property owners an opportunity to purchase flood insurance with actuarial-risk based premiums estimated from flood hazards depicted in the FIRMs of participating communities.

When the NFIP was established in 1968 there was no coastal analysis identified for mapping coastal flood hazards. In order to expedite publishing FIRMs for the County most coastal communities were mapped with approximate V-Zones ending at the shoreline, no inland coastal flooding was shown on most FIRMs. From the 1970s to the early 1980s, the procedures for identifying V-Zones resulted in FIRMs understating the true level of hazards and risks along the open coast and generally decreased mapping uniformity (Dewberry \& Davis, 1986). Guidance for the delineation of V-Zones was vague, resulting in wide variations based on the level of developed coastline, engineering judgment of vegetation influence to wave propagation, and historical information. During this period, consideration of dune erosion varied from the use of analytical models, site-specific historical data, or was not considered at all. By the mid-1980s, several storms along the Atlantic Coast and Gulf of Mexico resulted in extensive erosion and damage to areas that showed little or no flood risk on the effective FIRMs.

To address these inadequacies and inconsistencies, studies on dune erosion were conducted, and guidelines were subsequently developed to require the mapping of PFDs. In an effort to address concerns raised by stakeholders in the 1980s, FEMA initiated an evaluation of its current V-Zone mapping procedures. FEMA tasked Dewberry \& Davis with reviewing V-Zone mapping methodologies, evaluating and summarizing historic erosion events, and developing a technical basis for improving V-Zone mapping. In the 1986 publication, Assessment of Current Procedures Used for the Identification of Coastal High Hazard Areas (CHHA or V-Zones), Dewberry \& Davis documented a quantitative erosion analysis methodology based on pre- and post-storm profiles and dune crosssectional areas. The study also recommended that V-Zones along the open coast be re-defined to include the Primary Frontal Dune (PFD).

As part of this study, dune-face retreat cases were measured from a population of 30 storm events (Dewberry \& Davis, 1989). The collection of storm events had recurrence intervals ranging from 1.25 to 300 years, as determined by peak flood elevations using long-term gage records. In cases where 
multiple field profiles were measured, median erosion values were computed. Figure 1 shows the relationship between profile cross-sectional volumes eroded (as measured above the peak flood elevation) and return period for each of the retreat-case erosion events evaluated. After the original research documented in 1986, 8 additional storms were used to supplement the original storm population.

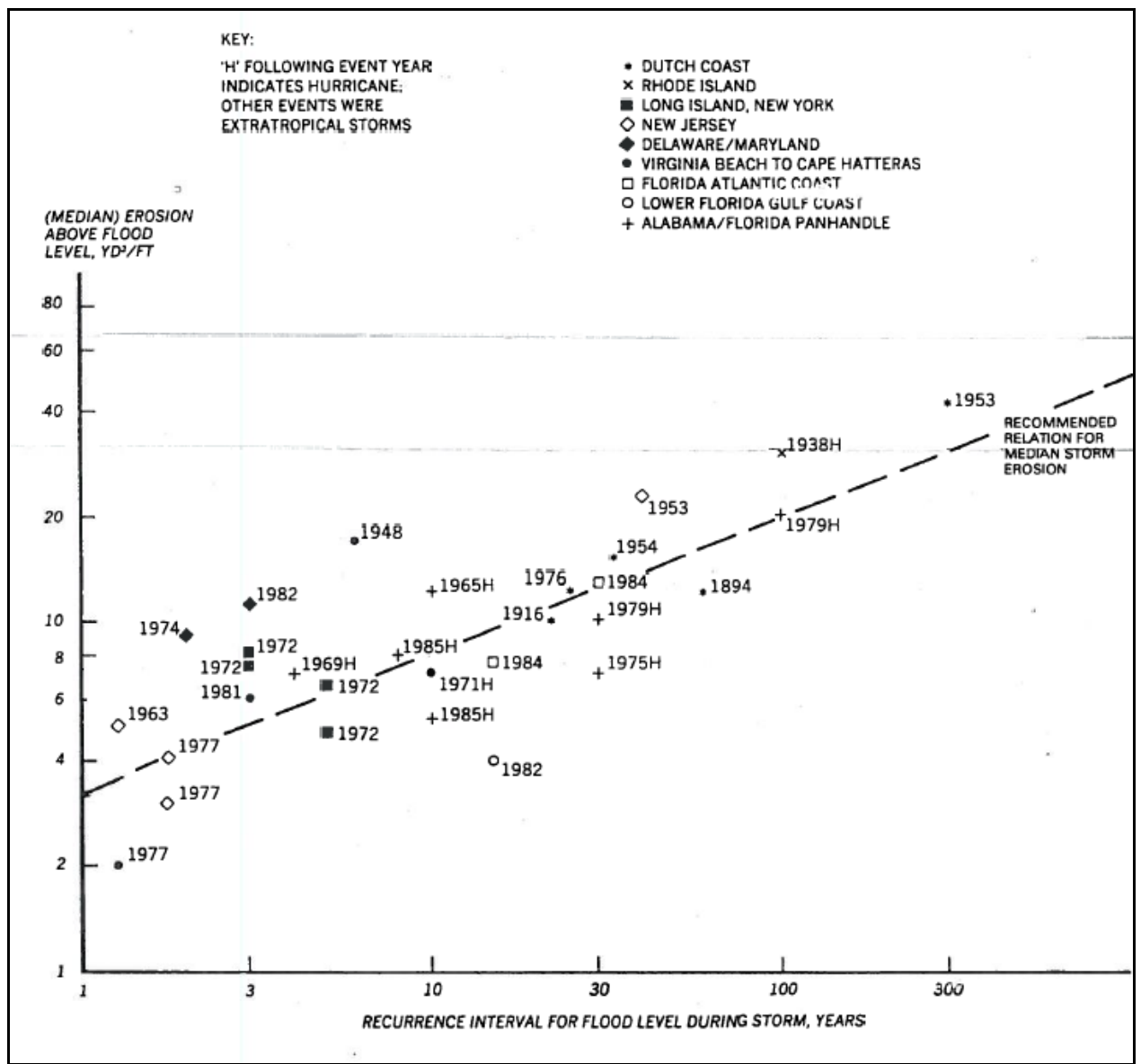

Figure 1. Median profile erosion versus reoccurrence interval (reproduced from 1986 Assessment of Current Procedures Used for the Identification of Coastal High Hazard Areas (V-Zones)).

Based on regression analysis performed by Hallermeier and Rhodes (1988), the median crosssection of the eroded dune due to the 1-percent-annual-chance event is 540 square feet per linear foot of shoreline, measured above the 1-percent-annual-chance water level. From this analysis, 540 square feet became the threshold value used to determine if a dune was substantial enough to withstand the erosive effects of a 1-percent-annual-chance storm event. For the 0.2-percent-annual-chance event, the threshold value is 1,030 square feet per linear foot of shoreline above the 0.2-percent-annual-chance Stillwater level (SWEL).

A simple geometric method was recommended to evaluate dune erosion for transect-based coastal hazard analyses based on what has ubiquitously become known as the "540 rule". Applying this method, dune reservoir volumes equal to or greater than 540 square feet per liner foot will be retreated; dune reservoir volume less than 540 square feet per linear foot result in a dune removal case.

Dune retreat geometry removes 540 square feet from the seaward portion of the dune reservoir measured above the 1-percent-annual-chance SWEL, and deposits the eroded material offshore of the dune. If the dune reservoir is computed to contain less than 540 square feet per linear foot, then a dune removal erosion analysis is applied, removing the dune above the dune toe using a 1:50 slope, consistent with observed post-storm profiles for major storm events. In both cases, whether removed or retreated, the geometry of the profile is adjusted to reflect that condition, which is then used during the application of the WHAFIS model to calculate overland wave heights.

The 1986 published findings, Assessment of Current Procedures Used for the Identification of Coastal High Hazard Areas (V-Zones), noted that there was significant uncertainty and variability in 
observed dune erosion, and further recognized that the proposed erosion methodology ignores important factors such as wave runup, wave overtopping, storm duration, sediment grain size, profile geometry, long-term erosion, and the cumulative influence of multiple storm events. In addition to the simplified erosion analysis, the report recommended that coastal high hazard zones along the open coast should be redefined to include the entire PFD. Four main reasons were provided to support this recommendation:

1. Evaluation of coastal dunes showed that in most observed dune erosion cases, the dune would be destroyed under 1-percent-annual-chance storm conditions.

2. If the dune feature were to survive the 1-percent-annual-chance event, the effects of wave runup and wave overtopping could still result in coastal hazards on the entire dune system.

3. NFIP regulations prohibited the alteration of sand dunes located in V-Zones, and consequently did not protect sand dunes that were not designated as V-Zones.

4. Should building on dunes be permitted by state or local ordinances, this recommendation was intended to impose adequate insurance rates and construction standards for those locations.

Based on the 1986 report, coastal high hazard delineation and erosion considerations were introduced to the Federal Register as a proposed rule, Coastal High Hazard Area and Erosion Considerations for Sand Dunes, on November 3, 1987 (52 FR 42117). The proposed rule used the findings from the 1986 study to justify the implementation of the cross-sectional erosion analysis and mapping of the PFD in a V-Zone. Six commentators from various private companies and government backgrounds reviewed the proposed rule and provided feedback (53 FR 16269). In general, comments were in support of the rule, but required some clarification to the proposed rule.

In addition to addressing comments, the final rule was amended to include definitions for "Primary Frontal Dune" and "Coastal High Hazard Area" on May 6, 1988. A figure of a sample profile was provided within the Federal Register to clarify evaluation criteria for dunes, such as showing the measurement of cross-sectional area and the location of the PFD and its inland limits. Per section 59.1 "Definitions" in 44 CFR, "the inland limit of the primary frontal dune occurs at the point where there is a distinct change from a relatively steep slope to a relatively mild slope".

Since the implementation of this rule in 1988, consideration of erosion and delineation of the PFD has remained in the guidelines for FEMA coastal flood studies along the Atlantic and Gulf Coasts. Recently, FEMA's updated 2015 Coastal Erosion Guidance notes that the dune erosion for a retreatcase profile should be measured above the elevation of the 1-percent-annual-chance SWEL, including wave setup. This is a notable change in methodology from the original dune erosion guidance, in which the cross-sectional dune area was measured above the 1-percent-annual-chance SWEL without the inclusion of wave setup. Additional FEMA documentation has been developed to supplement the rule with examples.

\section{Primary Frontal Dune Mapping Issues}

"Primary frontal dune (PFD) means a continuous or nearly continuous mound or ridge of sand with relatively steep seaward and landward slopes immediately landward and adjacent to the beach and subject to erosion and overtopping from high tides and waves during major coastal storms. The inland limit of the PFD occurs as the point where there is a distinct change from a relatively steep slope to a relatively mild slope." (44 CFR 59.1).

Because the FEMA definition of a PFD as outlined in 44 CFR 59.1 applies to multiple regions with multiple dune types and characteristics, it was written to encompass a range of attributes that could be applied broadly. The definition was deliberately constructed to be flexible to include all types of dunes that occur throughout the coastal plain; however, this flexibility, which can result in inconsistent PFD delineations, has become the basis of contention in different regions and has led to multiple appeals based solely on the interpretation and application of PFD definition and delineation.

Given the lack of specificity in the PFD definition, multiple dune heels can be deemed acceptable for the PFD extent (or PFD heel), which has allowed some communities to appeal based on using a more seaward ridge as the PFD. This can lead to development across the landward section of the dune field which then can destabilize the dune field and leaves the dunes subject to erosion or removal by storm events.

Some attempts have been made to quantify the feature to make it less subjective. In Massachusetts, a mathematical approach is used to determine the second derivative slope of the landward side of the dune, or determine the rate at which the backslope is changing, which is intended to identify where the dune slope changes from "relatively steep" to "relatively mild". Because dunes are subject to erosion, 
development, and migration, this mathematical approach does not always accurately capture the dune heel and must be confirmed against topography and ground data.

Based on engineering judgment, some areas of maximum inflection are not selected as the PFD location if the inflection is perceived to be due to a micro-topographic feature that is not regionally consistent with the dune feature. In general, a review of each study area using engineering judgment is still the primary means of determining the PFD location despite the defined criteria of slope change.

Figure 2 shows an example in Collier County, Florida, where low ground elevations, gentle slopes, and landward development contributed to subtle PFD heel inflections. In this particular case, the regionally consistent dune heel feature was best observed from the field as a low-magnitude inflection behind the dune, and not the largest topographic inflection viewed geospatially.

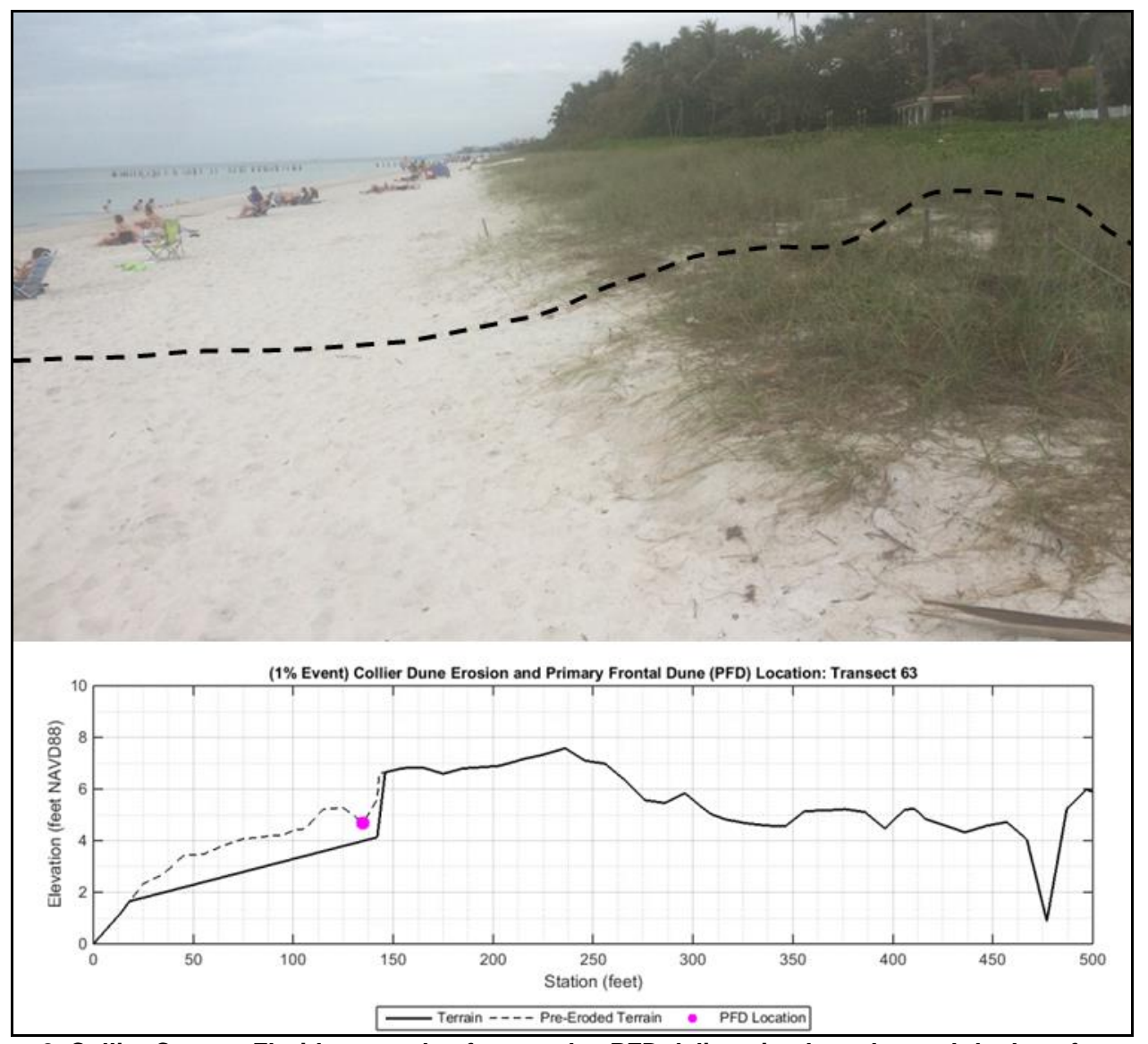

Figure 2. Collier County, Florida example of a complex PFD delineation based on subtle dune features

Dunes tend to form in systems that span several hundred feet to miles depending on the coastal environment. This aspect is complicated by the tendency of dune systems to meander, form multiple ridge systems, or merge into single dune ridge systems. Dune delineations then have to consider volume and the area's erosional history. Vegetation is also considered in PFD delineations as a sign of dune stability and relative age. Some Regions require this as a factor, with some conditions and exceptions, and other Regions look at it as a major factor but not as a requirement.

Another uncertainty factor in delineating a PFD is the nature of the dunes in general: dunes can change through natural coastal processes (accretion or erosion) or they can be removed or altered by development. In some cases where development has occurred on top of dunes, communities and residents have argued in appeals that because the dune has been built on, it is no longer a dune. In other cases, lots have been graded, moving the topographic inflection of a dune toe seaward of development (Figure 3). 


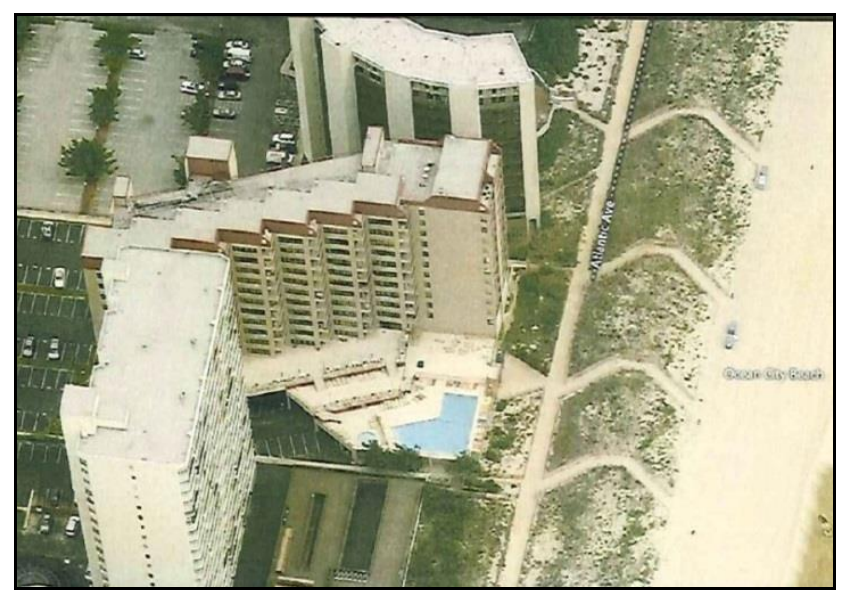

Figure 3. Example of encroachment onto the natural dune feature and PFD

44 CFR 59.1 defines the PFD as "a continuous or nearly continuous mound or ridge of sand." The phrase nearly continuous is an impetus for conflicting interpretation or judgment regarding when to maintain an unbroken delineation of the PFD line and when to allow breaks in the delineation. Breaks in a dune ridge can be caused by either natural processes (e.g., breaches caused by coastal storms) or from man-made impacts (e.g., removal of dunes for development, police and emergency access, walkways, or chronic damage to dunes from human traffic). The ambiguity of when to discontinue the PFD is exacerbated by the definition of a coastal high hazard area in 44 CFR 59.1 which requires that V-Zone extends "from offshore to the inland limit of a primary frontal dune." This means, at any gaps in the PFD, the mapping reverts to the WHAFIS results which often limits V-Zones to the beach, seaward of the heel of the adjacent PFDs. Inconsistent PFD delineations due to gaps in dunes can create the perception that coastal flood hazards decrease with decreasing dune size, or that areas without a dune have lower risks than areas that have maintained their dune.

To demonstrate the ramifications of the PFD delineation, an example of fluctuations in the dune ridge is provided in Figure 4. Note, this is for demonstration purposes and does not reflect the effective PFD delineation or SFHA mapping. This area was scrutinized in 2006, when a U.S. Senator submitted a letter on behalf of the city challenging "that the definition of a V-Zone unfairly penalizes residents who have a particularly wide frontal dune protecting their homes." The wider PFD at the western side shown in Figure 4 encroaches on the first row of homes, putting many of them in V-Zone. Eastward of these homes, the PFD is more seaward of homes and disappears entirely along two beach access parking lots, resulting in an inconsistent V-Zone delineation that is confusing for communities and property owners.

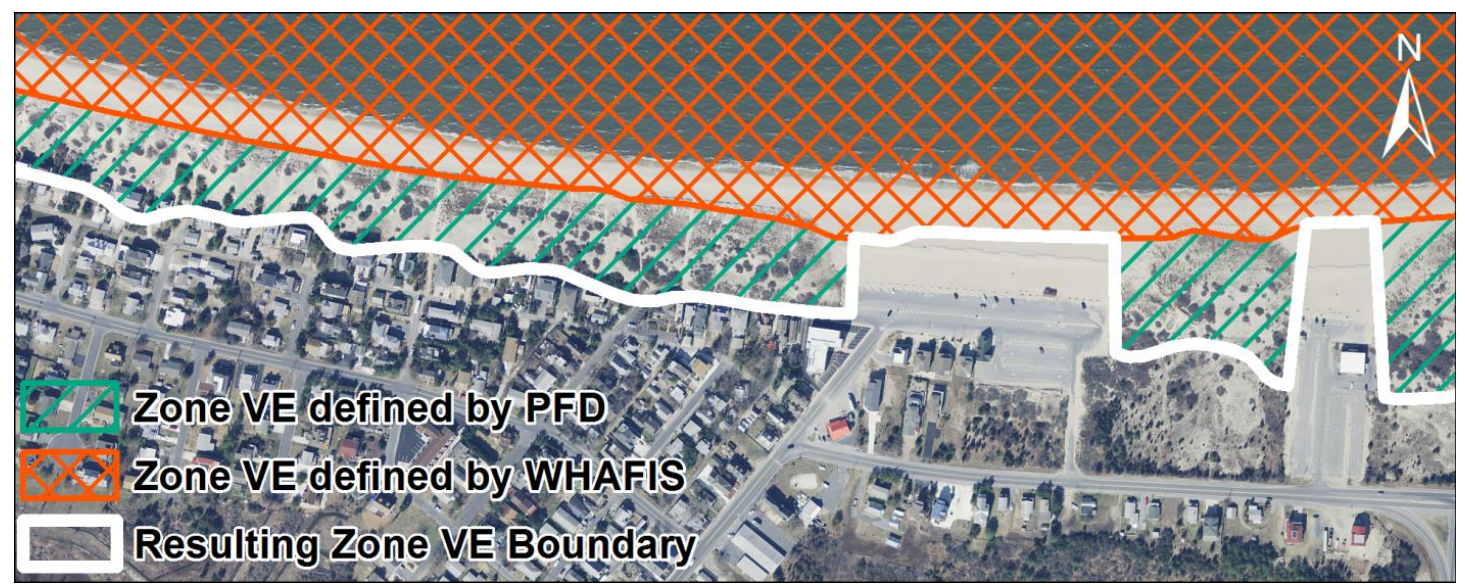

Figure 4. Example of V-Zone delineation with fluctuations and gaps in the Primary Frontal Dune

\section{Erosion Methodology Issues}

The FEMA dune erosion assessment procedure, also known as the "540 rule", focuses on erosion to the dune, and neglects erosion the surrounding beach experiences during storm events. The loss of sand during coastal storms can cause lowering of the beach berm and even extend the shoreline further inland. Beaches can naturally recover these losses over time; however, during the storm event, the 
eroded beach profile can allow larger waves to propagate inland and reduces the beach's ability to function as a barrier to mitigate storm surge.

Figure 5 shows an example of storm-induced beach and dune erosion in Ponte Vedra Beach, Florida. The erosion resulting from Hurricane Mathew and Hurricane Irma caused the beach berm, seaward of the dune, to be several feet lower than what was represented in the FEMA dune retreat profile.
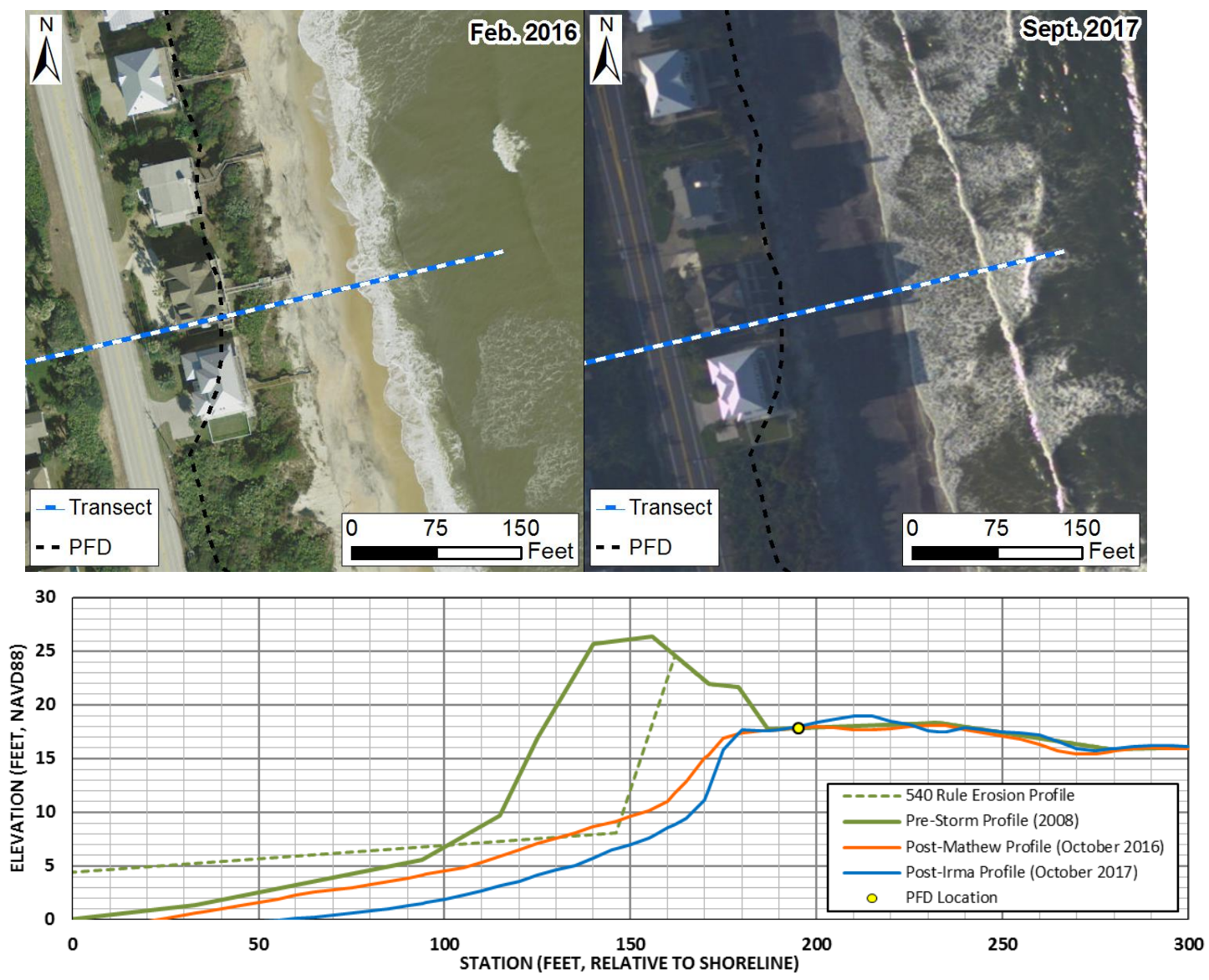

Figure 5. Ponte Vedra, Florida example of storm-induced erosion that caused more beach erosion than the FEMA erosion methodology.

Figure 6 illustrates this issue in Navarre Beach, FL, an area that experienced substantial erosion during Hurricanes Ivan (2004) and Dennis (2005). Both storms produced storm surge levels similar to the 1-percent-annual-chance storm surge; however, a comparison of the "540 rule" Erosion Profile and Post-Ivan Profile in Figure 6 show how severely the "540 rule" can underestimate erosion. Hurricane Ivan lowered the beach berm between 3 to 5 feet and receded the shoreline almost 100 feet. Less than one year later, Hurricane Dennis further lowered the already diminished beach and eroded the shoreline another 40 feet inland. 

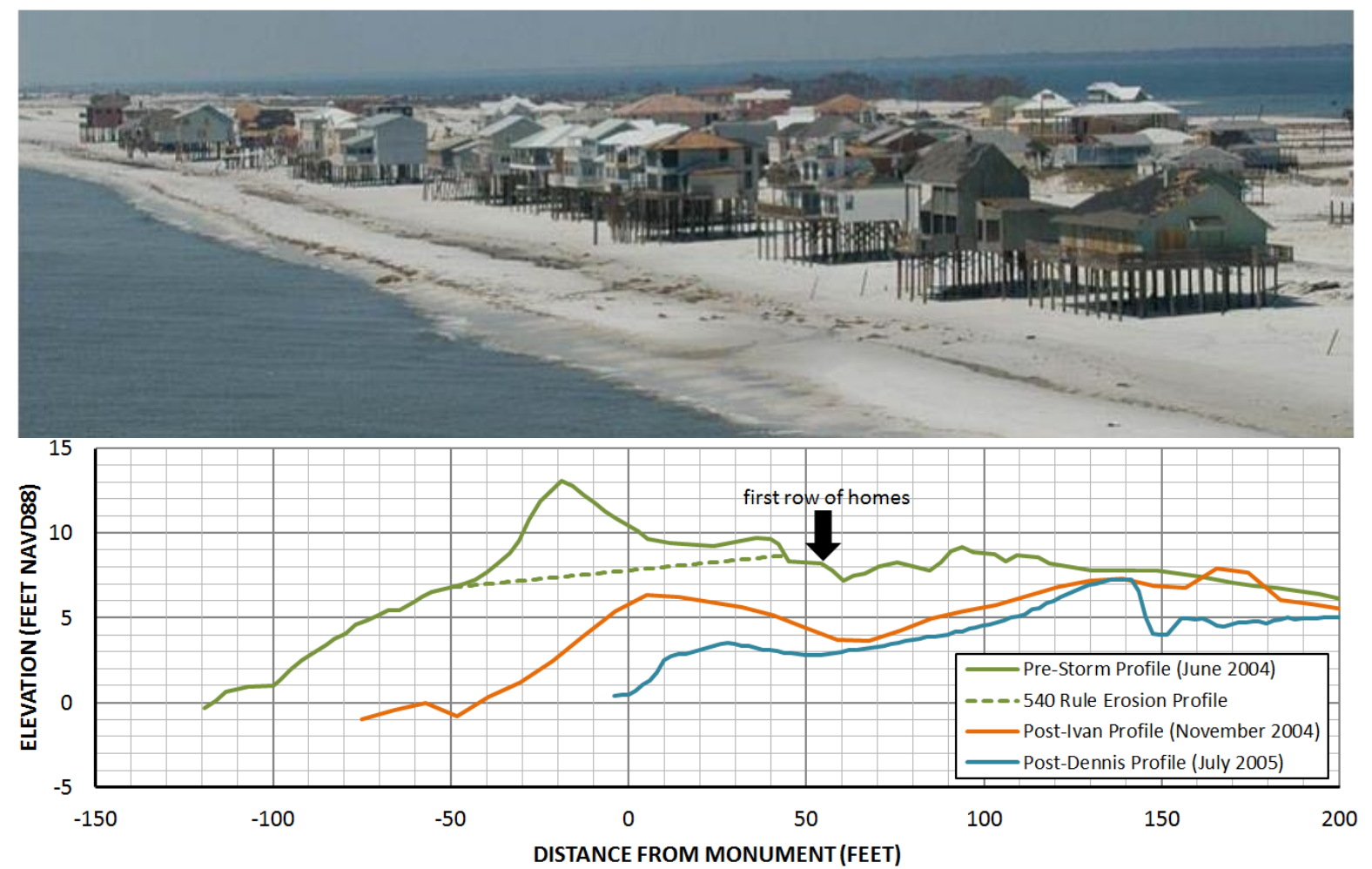

Figure 6. (TOP) Photo of beach lowering and absence of dune in Navarre Beach, FL after Hurricane Dennis (FDEP 2006); (BOTTOM) Beach profiles before Hurricane Ivan, after Hurricane Ivan, and after Hurricane Dennis from Navarre Beach, FL (FDEP 2004; USACE 2004; USACE 2005)

As previously described, the "540 rule" assumes larger dunes will stay intact with substantial erosion to the dune face and deposition at the seaward side of the dune. In Figure 7 two profiles from Seaside Park, NJ compare the retreated dune based on the "540 rule" and the measured erosion from Superstorm Sandy, which was similar to a 1-percent-annual-chance surge event for the area. The two profiles are less than 1,000 feet apart, but show a substantially different response to Superstorm Sandy and substantially different agreement with the "540 rule" profiles. The variability in accuracy of the "540 rule," even within a single town like Seaside Park, highlights the need for a more robust erosion methodology that considers more than the size of a dune relative to the total Stillwater.
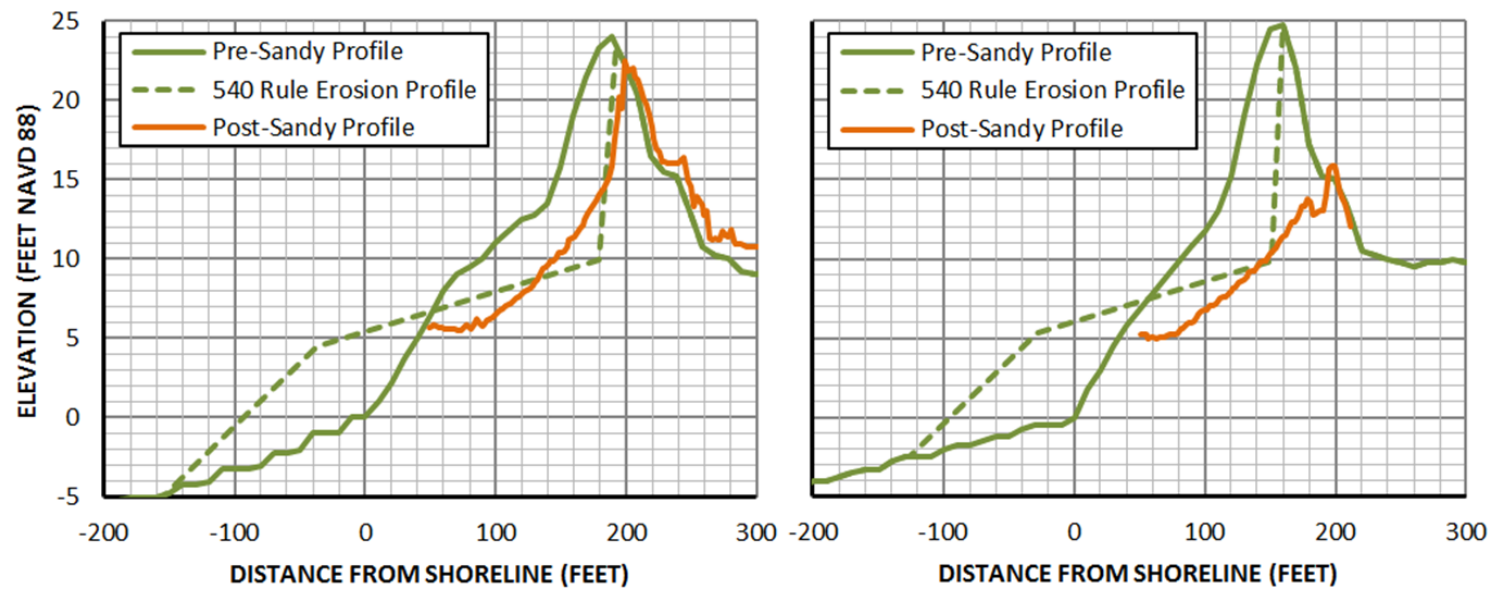

Figure 7. Beach profiles before and after Superstorm Sandy from the Borough of Seaside Park, NJ (USGS 2012), Left profile shows good agreement between FEMA erosion method and erosion from Sandy, right profile shows poor agreement.

Conversely, the "540 rule" can result in over prediction of erosion, particularly when the local dune geometry deviates from a classic, steeply peaked ridge, or when development along the dune limits erosion potential. For example, broad, low dunes that are slightly higher than the stillwater, but still exceed the "540 rule" criteria can result in hundreds of feet of dune retreat. Alternately, short dunes or 
sandy bluffs with a dune reservoir less than 540 square feet may result in a removal slope extending hundreds of feet inland, well beyond expected storm response. Figure 8 highlights the latter case in Brevard County, FL where standard dune removal yielded erosion extending inland of the first row of development and the nearby road. In this case, the Mapping Partners deviated from the "540 rule" to create a more representative profile, highlighting the need for improvements in erosion methodology.

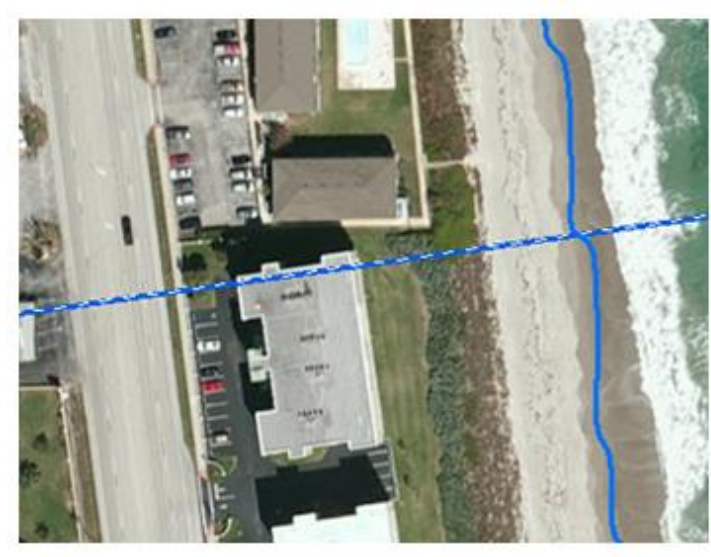

Figure 8. Standard removal slope based on dune reservoir less than $\mathbf{5 4 0}$ square feet

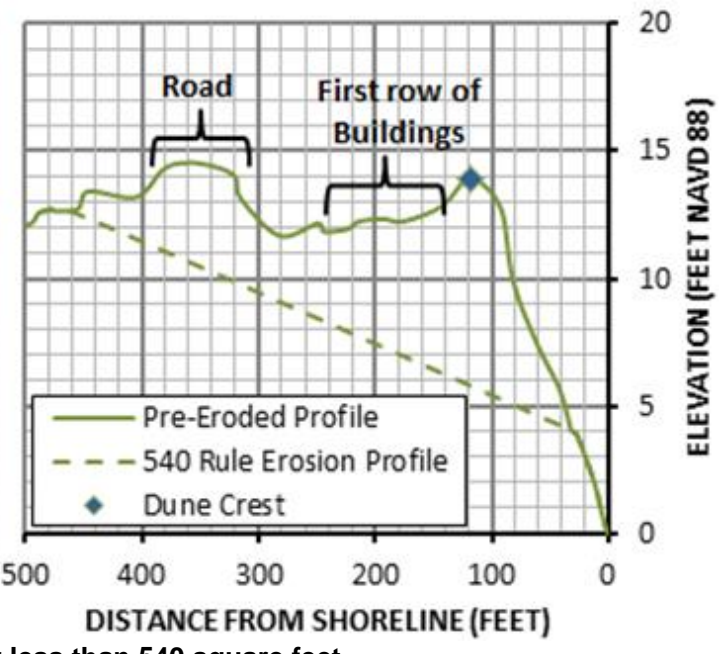

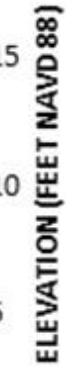

44 CFR 65.11 states that exceptions to the evaluation criterion of the PFD ("540 rule") may be granted with authoritative historical documentation at specific sites. This allows lower or higher values than standards to be used. However, higher values can incite intense public scrutiny and objections. In the Town of South Bethany, DE, a non-standard erosion analysis was performed after local officials submitted pre- and post-storm beach profiles to support more severe erosion conditions than the "540 rule" would produce and to use a retreat-style profile instead of removal profile. However, adjusting the erosion to be consistent with measured data resulted in an increase in the BFE due to the inclusion of wave runup hazards, which triggered sustained concerns from local residents and eventually initiated a lawsuit even though the study passed several rounds of independent technical reviews.

In addition to providing justification for alternative erosion approaches, historic erosion data is needed to evaluate erosion in sheltered areas and erosion of bluffs along the Pacific and the Atlantic shorelines. Unfortunately, historic data is typically unavailable. Since 1988 establishment of 540 square-foot method, there have been 40 or more storm erosion events nationwide with pre- and postevent profiles available to use if the 540 square-foot method is updated. However, that pre- and postprofile data is just 30 years of historic data that may not be representative of erosion trends or regional beach response to erosion events. This lack of historic erosion data does not automatically suggest sheltered sites are not subject to erosion; however, application of erosion at such sites will be difficult to justify without historic data. Applying erosion in sheltered areas is further complicated without historic data to support or contradict the "540 rule" which is based on open coast erosion. As a result, erosion analysis is typically not applied in sheltered/non-open coast areas; consequently, coastal flood hazards are potentially underestimated in such areas.

Similarly, historic and long-term site-specific data is needed to determine the eroded profile for bluff erosion along the Pacific and Atlantic shorelines. The Pacific methodology recommends that a minimum of two years of bluff erosion data be collected at each site for calibration of Sunamura's empirical equation $(1982 ; 1983)$, which is used to estimate erosion at the toe of a bluff. In addition, the Pacific methods for erosion in the Erosion Guidelines (FEMA, 2015) for erosion recommend collecting two to five years of bluff retreat data in order to perform a Monte Carlo simulation to estimate bluff-top retreat distances caused by undermining of the bluff. The historic data required for these calculations is not available for most coastal bluffs, a scarcity acknowledged in the Pacific Guidelines which states, "[The data requirements] are likely to limit the applicability of this approach for traditional FEMA coastal flood studies, unless these data are readily available at the beginning of the project." Recent coastal studies in California were unable to obtain sufficient historic data and were therefore unable to apply a bluff erosion analysis. 


\section{Other Issues Impacting Erosion}

Erosion analysis in the current FEMA FIS practice does not account for situations involving multiple storm events occurring at a specific location within a relatively short period of time. Multiple events can cause incremental erosion of dunes, which ultimately, when aggregated, result in significant erosion or loss of the frontal dunes. If a coastal area is impacted by more than one storm event of varying intensity within the same storm season or period, the erosion analysis for the subsequent events would not be representative of what might be modeled for one major event such as a $1 \%$ flood. In several instances, successive erosion occurs and has caused significant erosion or loss of the dune that might exceed what would be determined from traditional erosion treatment accounting for only the $1 \%$ event. The current FEMA methodology does not account for cumulative erosion caused by consecutive events.

Examples of cumulative impacts from successive events are: Hurricanes Dennis (1999) and Floyd (1999) in North Carolina; and Hurricanes Ivan (2004) and Dennis (2005) in the Gulf of Mexico, as well as the multiple Nor'easters hitting the New England area and the large Hurricanes hitting the Southeast and Gulf in more recent years. Cumulative erosion is recognized as a potential issue in the Dewberry \& Davis 1986 report, which states, "a moderate storm could significantly change the dune profile, making the dune vulnerable to overwash by a subsequent 100 -year storm. . . . Relatively common storms cause quite significant erosion: two 10-year storms will result in more total erosion than a single 20-year storm, and so on." Hallermeier and Rhodes note cumulative events have a high probability of occurring, but may contribute to a larger amount of dune erosion. "With a 10-year interval chosen between dune replenishments, notable expected storms (50\% risk) have recurrence intervals of 14.9 and 6.1 years. Those two storms could yield upper-dune erosion totaling 40 [square meters], nearly doubling advisable cross section" [1988].

FEMA's Coastal Construction Manual, Principles and Practices of Planning, Siting, Designing, Constructing and Maintaining Residential Buildings in Coastal Areas recommends that designers use a frontal dune reservoir of 1,100 square feet to withstand dune removal during the 1-percent-annualchance event [Jones, 2001]. Regarding cumulative impacts and limitations of the "540 rule", the Coastal Construction Manual states, "FEMA's 540 square feet rule does not account for the cumulative effects of multiple storms that may occur within short periods of time, such as occurred in 1996, when Hurricanes Bertha and Fran struck the North Carolina coast within 2 months of each other."

Another consideration is the duration and the speed of the storm which can impact the scale and extent of beach. Storm surge duration is often measured as the time span over which water levels remain considerably elevated above expected astronomical tides. Fast moving storms have different erosion effects on the coastal areas than slow moving storms. Storms with longer durations impose different erosion effects on the shorelines compared to shorter storms [Dewberry \& Davis 1986]. For example, a fast moving storm may only cause retreat of a dune system whereas a slow moving storm may completely remove and overwash the dune.

The speed is also correlated with the intensity (e.g., a lower intensity slow moving storm may cause more erosion of the PFD than a higher intensity fast moving storm). These effects need to be studied separately and the effects of the speed and duration of the storm need to be reflected in coastal erosion analysis. The potential effects of storm surge duration were noted in the original Dewberry \& Davis erosion methodology research. The report discusses the storm durations of the 8 hour long 1938 Hurricane and 60 hour long 1962 extratropical storm at Willets Point, New York, noting that the two storms had different erosive effects [1986].

Storm-induced erosion can lead to increased storm surge levels seaward of a dune and potentially impact the wave heights that may propagate inland during storm events. In the early 1980's a study in North Carolina identified the need to include erosion of the beaches and dunes in the storm surge modeling effort. For that effort, broad assumptions were made as to the eroded profile and incorporated into the storm surge model. However, in general, storm surge studies do not include alteration of the dune topography to simulate conditions that might actually occur during an event. In essence, dunes change dynamically during a storm event as does their ability to withstand storm surge levels whereas FEMA coastal studies model dunes statically throughout storm surge simulations (i.e., the dunes remain intact regardless of the surge levels).

Several demonstration studies have attempted to incorporate erosion into the hydrodynamic simulations with waves and water levels. The intent of these is to capture erosion of features such as beaches and dunes during the onset of a storm surge event. As observed in nature, erosion during a storm surge event is a progressive phenomenon. For example, as storm surge levels rise along a 
shoreline during the approach of a storm, the early phases of dune toe erosion occur followed by escarpment of the dune. Eventually the continuing escarpments advances until a point when the dune collapses at which point continuing wave runup and overtopping succumbs the dune to overwash fans deposits on the upland side of the dune heel or lee side of the dune ridge. Recent attempts have adjusted the digital train model by removing or eroding dunes (or ridges) a-priori and running storm surge simulations upon an "eroded" terrain modeling mesh (Spaulding, et al., 2017).

Although results are promising, further research and testing is needed to capture a broader range of the actual dynamics of erosion of a feature such as a dune (ridge) during an extreme surge simulation that would have varying results depending on the timing of peak tide water levels. In some instances portions of a dune ridge would not be overtopped, yet in others the ridge may be partially compromised, or worse completely removed. Simulations that adequately capture conservation of mass (e.g., dune sediments) so far are limited to very small (and highly dense) modeling domains. Scaling fully coupled 2D erosion-wave-water level simulations to regional modeling domains suitable for incorporating into current JPM-OS statistical methods is forthcoming perhaps with more research and development.

The Coastal Construction Manual suggests increasing the dune reservoir volume for design purposes because the "FEMA's 540 square-foot rule reflects dune size at the time of mapping and does not account for future conditions, when beach and dunes may be compromised by long-term erosion." Long-term erosion impacts coastlines and threatens the accuracy of floodmaps for coastal communities, especially for those with above average erosion rates. When the FEMA proposed rule, Coastal High Hazard Area and Erosion Considerations for Sand Dunes, was submitted for review in 1987, a state commentator suggested that FEMA incorporate long-term erosion rates of oceanfront shorelines (53 FR 16269). Ultimately, this recommendation was rejected, citing that consistent datasets for shoreline retreat rates do not currently exist for uniform consideration of long-term erosion. The response also noted that FEMA intends to maintain map accuracy by periodically updating coastal hazard maps. Unfortunately, it is not feasible to update maps on this frequency.

Even if maps are updated on a frequent basis (e.g., every 5-years), some communities such as Hunting Island, SC have recession rates that outpace the frequency of mapping updates (Figure 9). Hunting Island has historically experienced shoreline retreat of over 20 feet/year (Anders, et al., 1990). Frequent beach nourishments and groin construction have been used to slow the long term erosion along the island. Figure 9 below, shows the rapid shoreline change on a portion of Hunting Island, relative to recent preliminary mapping. In this portion of the island, surveyed monitoring cross-sections have recorded erosion rates between 15 and 30 cubic yards per year since 2007 (Coastal Science and Engineering, 2016). The 2017 imagery in Figure 9 shows amplified erosion due to the post-storm erosion effects from Hurricane Irma, but the overwash and breaching of the PFD along this island provides an example of an area that incurs a greater long-term risk than the current erosion assessment.

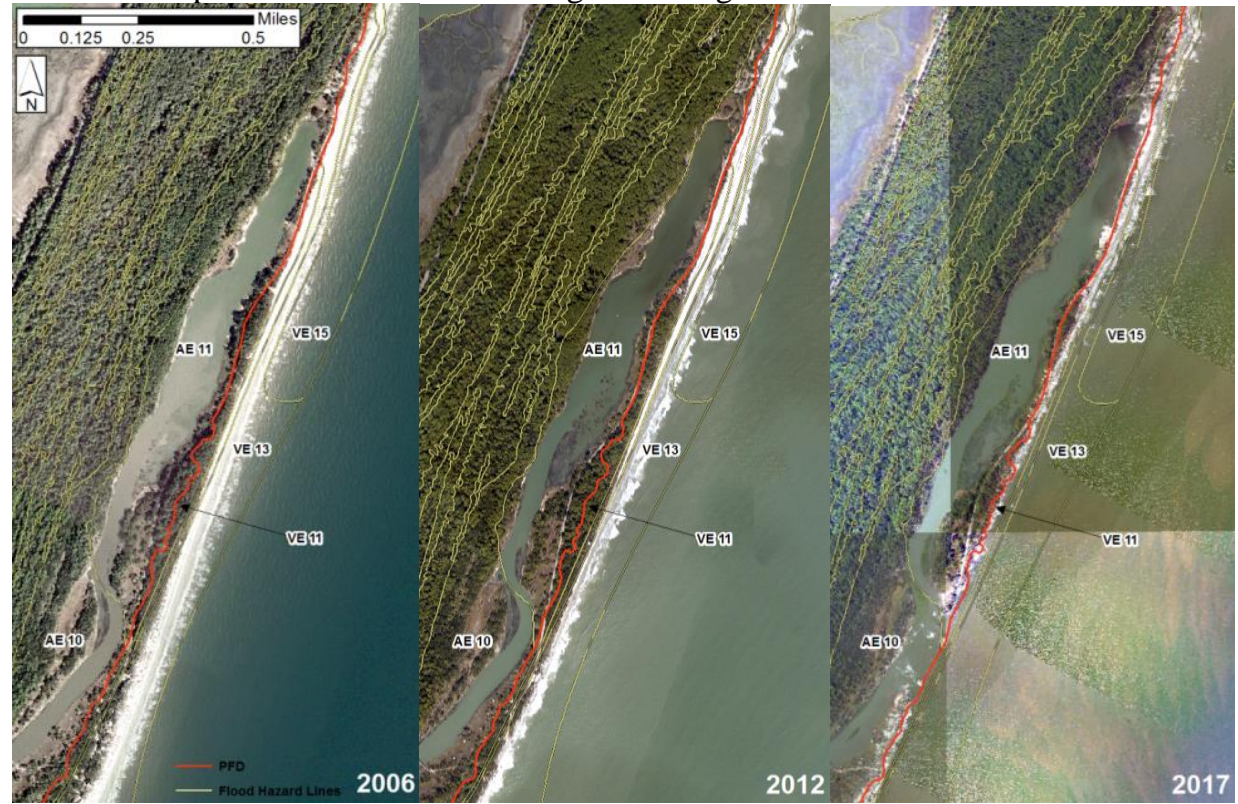

Figure 9. Hunting Island, SC shoreline change relative to preliminary flood mapping and PFD delineation. 
Since the implementation of FEMA's current erosion methodology, there have been several cases where the frequency of mapping updates has not kept up with the changes caused by long-term shoreline erosion rates. This points to the need for post-storm episodic erosion assessments, in addition to implementing a program of long-term shoreline change analysis and mapping within NFIP coastal studies (as supported by recent (2015-2018) TMAC recommendations).

In 1999, it was documented during an evaluation of coastal hazards study by Crowell, et al., that projected impacts of gradual erosion were not being considered in mapping and that gradual erosion was being considered only when an area is to be restudied and remapped. The study noted that without consideration of long-term changes in shoreline position, the delineation of risk can be misleading and would not reflect future risk posed to oceanfront properties. This may result in structures that are constructed to the current or effective BFE standards, and if built close to the shoreline may, after several years of erosion, become subject to inundation even during relatively low magnitude storm surges or by daily high tides.

\section{Recommendations for Change}

For the reasons outlined in this paper, recommendations to FEMA include:

1. Re-evaluate the methodology for calculating erosion hazards, and

2. Investigate alternatives to the automatic V-Zone designation for areas within the Primary Frontal Dune.

These recommendations are supported by external feedback provided to the Agency and strategic objectives set internally. Recently, FEMA released an updated Strategic Plan for 2018-2022. The plan provides a framework for supporting the United States before, during and after disasters. The updated priorities outlined, include Strategic Goal One, 'Build a Culture of Preparedness.' This goal includes Strategic Objective 1.1, 'Incentivize Investments that Reduce Risk' and 1.2, 'Close the Insurance Gap.'

Both of these could potentially be advanced if certain actions are taken regarding the PFD and erosion methodologies. For example, if the primary frontal dune was delineated for information purposes only, communities could begin to use it as a floodplain management tool. Without ties to flood insurance rates, using the line to support community action in protective measures would not be as controversial, especially given that many properties within the Primary Frontal Dune reside well above the base flood elevation. The frequent actions to push the line seaward - often influenced with a motive to reduce insurance prices - will reduce. Many states, such as Florida and Delaware, have designated areas along the coast where building is restricted to maintain the protective buffer of a beach. States without this may find the primary frontal dune as a feature to embrace as a similar tool, increasing mitigation investment along the coastline.

Basing the zone designations on model-based calculations may also be more actuarially sound in support of the National Flood Insurance Program. By defining the V-Zone as an area that is governed by 3 -ft wave heights, 3 -ft wave runup depths or splash overtopping rates, the hazard-based risk rating may be more aligned with actual risk, providing more graduated rates along the coastlines. The regulatory floodplain will appropriately designate areas that are at risk for both erosion and increased wave action. Currently, an erosion loading factor is applied uniformly across the coasts of the country when calculating flood insurance premiums, without suitable gradation of risks based on differing hazards.

By having mapping and rate setting be based in hazard analysis, and not complex regulations, the recommendations in this paper also align to FEMA's Strategic Objective 3, 'Reduce the Complexity of FEMA.' There are estimates (FEMA, 2008) that show fewer than 70,000 people reside in primary frontal dune areas, given the narrow reaches of these shore-parallel zones. This number is quite small compared to the approximate 8,651,000 people that reside in the $1 \%$-annual-chance coastal flood hazard areas (Crowell, et al., 2010), yet appeals and controversy disproportionally come from issues around the Primary Frontal Dune.

Finally, technical credibility has long been a priority within the mapping program (Risk MAP) to support the delivery of FIRMs. Without it, map acceptance for both flood insurance purchase and floodplain management is problematic. This has been demonstrated consistently throughout the history of the NFIP, where the most contentious resistance is due to accuracy disputes and perceived lack of fidelity in modeling and mapping. A focus of the Risk MAP program has been to use the best available science and data to deliver accurate and reliable mapping to communities. This has been achieved through rigorous data usage, peer-reviewed modeling, and adherence to mapping standards. 
Hurricane Katrina, in 2005, ushered in a new era of modeling methodology in the coastal program, resulting in a dramatic enhancement of mapping in coastally influenced areas across the United States. A significant effort was undertaken in updating the guidance supporting methods and models used for these coastal studies, vetted through world renowned subject matter experts in coastal sciences. The modeling utilized in coastal mapping is aligned with the state of the art practices, particularly with respect to storm surge modeling, that is used to develop Stillwater elevations prior to overland wave modeling and mapping. The process to develop Stillwater elevations can take several years, cost millions of dollars, and be exceptionally computationally intensive. As a result, these aspects of the modeling effort are sought after by the scientific community and other federal agencies.

However, despite the advances in the Stillwater modeling, erosion is still based on separate modeling methods developed several decades ago - creating a large disconnect in level of effort and technical credibility between two important aspects of a coastal study. There are now more advanced models or modeling suites that couple dynamic physical processes that can allow site-specific, tailored evaluation of erosion hazards. Such models can be coupled with coastal processes to capture the dynamic processes that occur during a storm itself and the dynamic response of the shoreline versus the disparate treatment applied in an isolated and static manner under current practices. Coastal science is constantly evolving, concurrently with computational advances, providing for the possibility of additional models being available in the future.

Utilizing scientifically sound and modernized methodologies to accurately calculate erosion risk is critical to continuing the technical credibility of coastal FIRMs. FEMA has an imperative to review the level of erosion that can occur at multiple frequencies. Providing a thorough profile of risk exposure along the coastline will assist with providing a site-specific, actuarial sound categorization of hazards. Using the primary frontal dune as a mechanism to identify and protect our dune systems is appropriate and likely welcomed by those that manage floodplains. Alternative methods improve the technical credibility of the mapped flood hazards should be considered.

\section{ACKNOWLEDGMENTS}

This work was funded by FEMA to evaluate recommendations to changes in the erosion and primary frontal dune methodology. The research into recommendations is continuing and does not reflect the final position of the Agency.

\section{REFERENCES}

Anders, F. J., D. W. Reed, and E. P. Meisburger, 1990. Shoreline movements: report 2: Tybee Island, Georgia, to Cape Fear, North Carolina, 1851-1983. Tech Rept CERC-83-1, CERC-Waterways Experiment Station, USACE, Vicksburg, MS.

BakerAECOM, 2012. Task Order 75: Georgia-Northeast Florida Flood Insurance Study, IDS1: Section 2 - Technical Approach - Topographic/Bathymetric Digital Elevation Model, prepared for Federal Emergency Management Agency.

Bellomo, D., Crowell, M., 2010. FEMA's Coastal Population Study: Comments on Data Accuracy, Current Initiatives, and Future Risk. Journal of Coastal Research. Vol. 26, No. 2, pp 199-200.

Carper, 2006. Letter to Daniel Shulman, FEMA Congressional Affairs Representative.

Crowell, M., Coulton, K., Johnson, C., Westcott, J., Bellomo, D., Edelman, S., Hirsch, E., 2010. An Estimate of the U.S. Population Living in 100-Year Coastal Flood Hazard Areas. Journal of Coastal Research. Vol. 26, No. 2, pp 201-211.

Dewberry \& Davis, 1986. Assessment of current procedures used for the identification of coastal high hazard area (V-Zones).

FEMA, 2008. Coastal AE Zone and V-Zone Demographics Study and Primary Frontal Dune Study to Support the NFIP. Washington, DC: Federal Emergency Management Agency Technical Report, 98p.

FEMA, 2010.The Impact of Climate Change on the National Flood Insurance Program and Improving Coastal Floodplain Mapping, Primary Frontal Dune V-Zone and Coastal Special Flood Hazard Area Studies.

FEMA, 2015. Guidance for Flood Risk Analysis and Mapping: Coastal Erosion. Federal Emergency Management Agency. Washington DC.

Federal Register, Rules and Regulations, 1988. Vol 53. No. 88. (53 FR 16269).FDEP 2004. Regional Coastal Monitoring Data: Profile Survey Data. 
Florida Department of Environmental Protection, 2006. Hurricane Dennis \& Hurricane Katrina Final Report on 2005 Hurricane Season Impacts to Northwest Florida.

Hallermeier and Rhodes, 1988. "Generic treatment op dune erosion for 100-year event". Coastal Engineering Proceedings. No 21, 1988.

Jones, C., 2001. Coastal Construction Manual: Principles and Practices of Planning, Siting, Designing, Constructing and Maintaining Residential Buildings in Coastal Areas. Diane Publishing.

South Carolina Department of Natural Resources, AECOM (2015), South Carolina Coastal Flood Study Technical Report, Intermediate Data Submittal 4 \& 5, Beaufort, SC.

Sunamura, T., 1982. A predictive model for wave-induced cliff erosion, with application to Pacific coasts of Japan, Journal of Geology, 90, 167-178.

Sunamura, T., 1983. CRC Hand Book of Coastal Processes and Erosion, Chapter 12: Processes of Sea Cliff and Platform Erosion, CRC press, Inc.

USACE, 2004. JALBTCX Post-Hurricane Ivan Topo/Bathy Lidar: Alabama, Florida.

USACE, 2005. JALBTCX Post-Hurricane Dennis Topo/Bathy Project, Alabama and Florida Coasts.

USGS, 2012. EAARL-B Coastal Topography: Post-Sandy. 